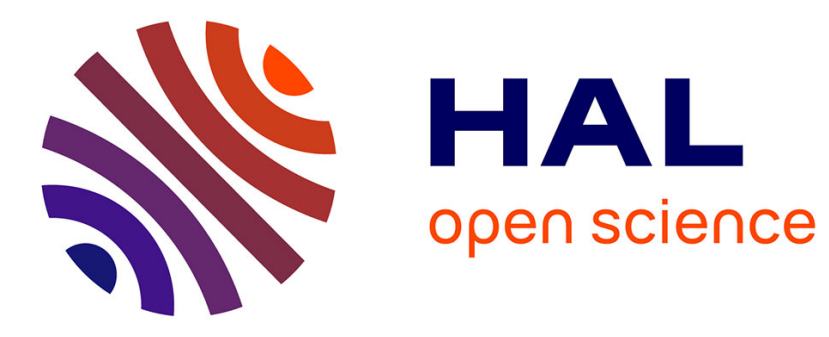

\title{
Are paedomorphs actual larvae?
}

\author{
Alicia Tribondeau, Laurent M Sachs, Nicolas Buisine
}

\section{To cite this version:}

Alicia Tribondeau, Laurent M Sachs, Nicolas Buisine. Are paedomorphs actual larvae?. Developmental Dynamics, 2021, 250 (6), pp.779-787. 10.1002/dvdy.304 . hal-03193617

\section{HAL Id: hal-03193617 https://hal.science/hal-03193617}

Submitted on 8 Apr 2021

HAL is a multi-disciplinary open access archive for the deposit and dissemination of scientific research documents, whether they are published or not. The documents may come from teaching and research institutions in France or abroad, or from public or private research centers.
L'archive ouverte pluridisciplinaire HAL, est destinée au dépôt et à la diffusion de documents scientifiques de niveau recherche, publiés ou non, émanant des établissements d'enseignement et de recherche français ou étrangers, des laboratoires publics ou privés. 


\section{Are paedomorphs actual larvae?}

Alicia Tribondeau, Laurent M. Sachs and Nicolas Buisine*

UMR7221 Physiologie Moléculaire et Adaptation, Centre National de la Recherche Scientifique, Muséum National d'Historie Naturelle, 7 Rue Cuvier, 75231 Paris Cedex 05.

Correspondance: UMR7221 Physiologie Moléculaire et Adaptation, Centre National de la Recherche Scientifique, Muséum National d'Historie Naturelle, CP32, 7 Rue Cuvier, 75231 Paris Cedex 05. buisine@mnhn.fr

Running title: Paedomophs $\approx$ larvae ?

Keywords: Urodeles, paedomorphosis, metamorphosis, thyroid hormone signaling, post embryonic transition

\section{Bullet points:}

- metamorphosis is widely believed to be the post embryonic transition for all amphibians

- paedomorphs retain larval characters and are perceived as larvae even as reproductive adults

- recent genomic data suggest a cryptic post-embryonic transition between larval and paedomorphic stages

- metamorphosis may be uncoupled from post embryonic transition in paedomorphic species

Grant Sponsor and Number:

MNHN ATM "XtransVies"

MNHN ATM "AMADE"

MNHN ATM "Ambystome"

MNHN ATM "Caudanoure"

CNRS PEPS ExoMod "Triton"

MNHN pre-doctorate studientship

MNHN post-doctoral fellowship 


\section{Abstract}

Amphibians display very diverse life cycles and development can be direct, where it occurs in ovo and a juvenile hatches directly, or biphasic, where an aquatic larva hatches and later undergoes metamorphosis followed by sexual maturation. In both cases, metamorphosis, corresponds to the Post Embryonic Transition (PETr). A third strategy, only found in Urodeles, is more complex as larvae reach sexual maturity before metamorphosis, which can become accessory. The resulting paedomorphs retain their larval characters and keep their aquatic habitat. Does it mean that paedomorphs do not undergo PETr?

Recent work using high throughput technologies coupled to system biology and developmental endocrinology revisited this question and provided novel datasets indicating that a paedomorph's 'larval' tissue undergoes a proper developmental transition. Together with historical data, we propose that this transition is a marker of the PETr, which would be distinct from metamorphosis. This implies that 1 ) complex life cycles would result from the uncoupling of PETr and metamorphosis, and 2), biphasic life cycles would be a special cases where they occur simultaneously. 


\section{Amphibians metamorphosis}

Amphibians display a remarkable diversity of life cycle strategies ${ }^{1}$, resulting in part from developmental plasticity. Although modern amphibians are often found at border-habitats between water and land, their plasticity allowed them to colonize extreme (desert) or almost water-less (trees) environments.

Amphibian metamorphosis is the striking and spectacular developmental process by which an aquatic larva (tadpole) transforms into a terrestrial animal (although some adults remain in the aquatic habitat). The profound anatomical changes, resorption of larval features (such as tailfin and gills) and development of novel body parts (limbs, skeleton reshaping and ossification) occur simultaneously with sharp physiological, cellular and molecular transitions ${ }^{2}$. As such, this transition is often referred to as the post embryonic transition (PETr). The cascades of events leading to metamorphosis have been the focus of numerous studies over the last two decades, and a clear picture of the control of metamorphosis emerged.

From a developmental biologist and molecular biologist point of view, most of our current knowledge on the physiological control and the cellular and molecular mechanisms of metamorphosis has been established using Anurans, and in particular in Xenopus species. The strength of these models is not limited to the fact that metamorphosis is a striking ("meta") change of body form ("morph") (Figure $1 \mathrm{~A}$ ) where defects often lead to highly contrasted phenotype, it also lies in their short metamorphosis duration ( one-two weeks) and easy endocrine manipulations by the simple addition of hormones to the rearing water. Combined with genomic resources available since the early 2000s, Xenopus metamorphosis is the leading model in the field of amphibian metamorphosis. The second key model is the Mexican axolotl, Ambystoma mexicanum, as the textbook example of alternative life cycle and accessory metamorphosis, although much less is known at the molecular level.

In this perspective, we challenge the historical view shared by many developmental biologists and physiologists that metamorphosis is the PETr, a statement which can be summarized with the pseudo-formula "M=PETr". The recent use of functional genomics at key and understudied developmental stages in Axolotl brings new light onto its apparent lack of metamorphosis. We argue that 1 ) larvae and paedomorphs do not only differ by their level of sexual maturation but they may represent two developmental stages per se, 2) the transition between larval and paedomorph stages is the PETr, and 3) metamorphosis and PETr are two distinct transitions that may be uncoupled from each other. The argument is based on a combination of developmental endocrinology, transcriptional regulation and system biology. We will review briefly these points before addressing the argument. 


\section{What we know from Anurans on the control of metamorphosis by TH}

\subsection{In Anurans, metamorphosis marks the post embryonic transition}

Tadpoles are anatomically adapted to aquatic life and display water specific features (gills, efficient swimming powered by a long tail and tailfin...). Oxygen uptake is provided by gills and transported by larval haemoglobin isoforms ${ }^{3}$. Another feature of tadpoles is that their skeleton is also entirely made of cartilage.

During metamorphosis, virtually all tissues disappear or are remodeled, the skeleton is reshaped and ossifies together with limb organogenesis. The new triangular skull shape provides the binocular vision adapted for prey hunting. Skin transitions to a thick dermis underneath a multilayered epidermis, with a well developed pigmentation and abundant mucous glands ${ }^{3}$. At the metabolic and molecular level, globins and myosin switch to an adult form with lower affinity to oxygen. Given the wealth of these anatomical changes and the short time scale involved, there is little doubt that metamorphosis coincides with the PETr (Figure $1 \mathrm{~A}$ ).

\subsection{Endocrine control of metamorphosis}

Two main endocrine systems control metamorphosis. The first one is the thyroid hormone (TH) axis, mediated by a set of small tyrosine-derivatives containing three or four iodine atoms. Before metamorphosis, THs synthesis is under the control of the hypothalamopituitary axis where $\mathrm{CRH}$ produced by the hypothalamus stimulates the release of TSH by the pituitary, which in turn signals the thyroid gland to synthetize and release $\mathrm{THs}^{4,5}$. Prior to metamorphosis, TH levels progressively increase in the body. Blocking TH synthesis and/or release with goitrogens or other compounds (propylthiouracil, potassium perchlorate, iopanoic acid) efficiently delays or prevents metamorphosis ${ }^{6,7}$.

TH availability at target tissues is in part controlled by deiodinases (reviewed by ${ }^{8}$ ), which help coordinate the timing of metamorphic changes between organs. These enzymes (Dio2, Dio3) remove iodine atoms from $\mathrm{TH}$ and ensure the activation of the hormone and its degradation into metabolites with reduced (and somewhat different) biological activity 9,10. For example, in Xenopus, Dio3 expression is strongly expressed during late prometamorphosis and until the end of hind limb growth, which helps protect tail muscle cells from $\mathrm{TH}$ action and delays tail resorption ${ }^{11}$, thereby ensuring proper locomotion with tail or legs during the whole metamorphosis process. Together, these enzymatic activities often display opposite regulation and fine tune local levels of bioactive hormones.

Although this is not the subject of this perspective, the gluco-corticoid (GC) axis is also an essential component. The connection between GC axis and metamorphosis has been known for decades ${ }^{12-14}$, but came to new light recently with Xenopus knock out mutant of GC receptors, which die at metamorphosis ${ }^{15}$. GC release by adrenal glands is controlled by the hypothalamo-pituitary axis, where $\mathrm{CRH}$ production by the hypothalamus induces ACTH release by the pituitary. It is remarkable that both $\mathrm{TH}$ and GC signaling only depend on $\mathrm{CRH}$ before metamorphosis and depend on $\mathrm{CRH}$ and $\mathrm{TRH}$ after. There are also deep 
connections between the two pathways at the molecular level at target tissues, where GC regulate Dio2/3 and TH regulate GC metabolizing enzymes. TH and GC signaling thus compose an intertwined interface allowing the integration of endogenous and external cues dictating metamorphosis.

\subsection{Mode of action of $\mathrm{TH}$}

At the molecular level, TH action is mediated by specific nuclear receptors (THRs), which act both as hormone-specific receptors and transcription factors. THRs have diverse effects and act both as activating and repressing transcription factors ${ }^{16}$. In absence of ligand, THRs are bound to DNA and repress transcription of target genes by recruiting transcriptional co-repressors. TH binding induces THRs conformational changes releasing co-repressors and the subsequent recruitment of transcriptional co-activators, ultimately leading to the transcriptional activation of the target genes. This ensures a clear switch of functional state typical of developmental transitions. Although this genetic circuit is structurally shorter than the "double negative gates" commonly found in genetic networks controlling early development ${ }^{17}$, they both serve the same purpose of canceling background transcriptional noise and secure stage-specific gene expression. The dual action mechanism of THRs is at the root of the complex phenotype of THR CRISPR mutants in Xenopus at metamorphosis and are the key regulators of metamorphosis timing

18,19. Typically, the order of magnitude of $\mathrm{TH}$ transcriptional responses is robust and involves two to five thousands genes. Although the set of direct target genes is not fully known and is highly variable between tissues and cell types, a few of them are found in virtually all tissues and are used as markers of a canonical TH transcriptional response (strom3, thbzip, klf9, thra/b, see ${ }^{20,21}$ ), and thus markers of the onset of metamorphosis. Molecular cascades of signal transduction and transcriptional responses are so well conserved through evolution that Xenopus metamorphosis has been the leading model to decipher the action mechanisms of THs ${ }^{18,22}$.

\subsection{Is metamorphosis equivalent to the perinatal period of mammals ?}

The primary response to the rising levels of $\mathrm{TH}$ prior to metamorphosis is the strong transcriptional reprogramming in target tissues, including the induction of klf9 and (the auto-induction of) thra/b expression itself, which fuels the TH response further by forming a one-way logic gate subcircuit. The perinatal period of mammals has many features similar to metamorphosis: a rapid change of ecological niche (the transition from water to air), a sharp peak of circulating $\mathrm{TH}$ and a canonical $\mathrm{TH}$ transcriptional response ${ }^{5,23}$. The words of Jacques Legrand highlight the parallel between metamorphosis and perinatal period: "Without a minimum of thyroid hormone at the right time, a tadpole does not become a frog and a human baby becomes a cretin". At the functional level, fetal protein isoforms (e.g. haemoglobin, myosin) are replaced by their juvenile/adult counterpart. In fact, the similarities between metamorphosis and the perinatal period are so strong that it has been proposed to be a form of "subtle" metamorphosis ${ }^{2,24}$. Implicitly, this statement also postulates that metamorphosis is de facto the post-embryonic transition marking the end of 
larval development (M=PETr). Unfortunately, this case is ambiguous. By definition, a key defining feature of metamorphosis is a drastic change of form, which subsequently imposes a change of habitat or ecological niche. In the case of mammals, this is clearly not the case since birth does not correspond to a spectacular change of form (hence the necessity to use the qualifier "subtle").

\section{Complex life cycles and their connexion with TH signaling ?}

\subsection{The diversity of life cycle transitions in urodeles and the timing of metamorphosis}

In Urodeles, a vast group of amphibian species across all continents, metamorphosis may not be obligatory, and life cycles can be quite diverse and more complex. The most comon case is a biphasic life cycle, where larvae hatch from the egg before undergoing metamorphosis at later time (Figure $1 \mathrm{~B}$ ). This is also the canonical life cycle of Anurans. The second case is direct development (also found in Anurans), where a juvenile directly hatches from the egg and metamorphosis is thought to occur in ovo (Figure $1 \mathrm{C}$ ). In both cases, direct development and biphasic life cycle, sexual maturity happens after metamorphosis. Urodeles display an alternative life cycle, where sexual maturity can occur before metamorphosis, which in this case can be facultative. The resulting sexually mature animals, called paedomorphs, retain anatomically larval characters (gills, tailfin, etc) and live in aquatic habitats (Figure $1 \mathrm{D}$ ). In these species, paedomorphosis can be obligatory or facultative, as some species can undergo metamorphosis later in life (e.g. Axolotl) and some never do (e.g. Necturus, and the cave dwelling Proteus). In Plethodontids and Ambystomatids, paedomorphosis may have evolved independently several times ${ }^{25,26}$. In terms of ecology, paedomorphosis relaxes the constrains related to the shift of ecological niche imposed by metamorphois and allows greater flexibility for choice of habitat, depending on biotic (predators, population density) and abiotic (water level) cues. In this regard, the crosstalks between TH and GC (i.e. stress) signaling highlight the deep connection between the endocrine regulation of developmental transitions and adaptative processes. Finally, some species display an even greater flexibility of life cycle (e.g. the palmate newt Lissotriton helveticus and some Plethodontids), where paedomorphosis is not obligatory and animals can engage either to paedomorphosis or metamorphosis depending of various internal and external signals ${ }^{26-28}$.

\subsection{The paradox of paedomorphic species and the expected defect(s) in $\mathrm{TH}$ signaling}

What is the molecular determinism of paedomorphosis ? According to the dogma, paedomorph are long lived, sexually mature animals 'stuck' at larval stage. It should be noted that from an ecological point of view, it is well established that paedomorphs often differ from larva not only by their size but also in color and/or behavior, thus suggesting different developmental stages. Nonetheless, this fact has puzzled scientists for so long 
that the term 'permanent larvae' ${ }^{29}$ was coined to describe them (even for species that undergo metamorphosis later in life), and more recently with the "forever young" Axolotl ${ }^{30}$. Given that metamorphosis onset is controlled by the TH axis, research focused mostly on finding TH signaling defects. Unfortunately, no defect could be found in Axolotl, where thyroid gland and THRs proved to be fully functional ${ }^{30,31}$, TH strongly induces klf9 and thbzip gene expression, although levels of circulating $\mathrm{TH}$ are relatively low ${ }^{32}$. In Axolotl, it is therefore admitted that metamorphosis (and thus PETr) occurs only after GC axis activation and its synergistic effect on $\mathrm{TH}$ metabolism, leading to a rise of endogenous $\mathrm{TH}$ levels ${ }^{8,14,30}$. In Plethodonthid salamanders, TH release and sensitivity of target tissues may also be important contributing factors controlling life cycle strategies ${ }^{33}$, illustrating that this fact may be a very general feature of paedomorphosis ${ }^{26}$.

\subsection{An early peak of TH, in Axolotl...}

At the early 80's, Rosenkilde et al. ${ }^{34}$, reported a progressive and transient increase of $\mathrm{TH}$ as soon as three weeks post-hatching in Axolotl together with Dio2 and the corresponding decrease of Dio3. This period, that we called HTP for High Thyroid hormone Period ${ }^{35}$, corresponds to the stage where the related species Pleurodeles waltii and Ambystoma maculatum undergo metamorphosis but Axolotl doesn't ${ }^{34,36}$. Brown ${ }^{37}$ later showed a progressive radioactive iodine uptake located at the thyroid gland, at the same stages. Surprisingly, TH treatment of young larvae results in a slight regression of larval traits, especially gills, before a phase of rapid and extended growth leading to overgrown features. This was the first indication of an early TH sensitive period distinct from metamorphosis. Circulating levels of T4 in Anurans and Urodeles (metamorphosing and non-metamorphosing) is quite variable, but still fall within the 0.1 to $2.0 \mathrm{ng} / \mathrm{mL}$ range, including Axolotl late paedomorph ${ }^{32,50-52}$. In metamorphosing species, these levels rise sharply at metamorphosis up to $\sim 5$ to $30 \mathrm{ng} / \mathrm{mL}^{52-55}$, which is very similar to the level reached during the transient surge of T4 at HTP in Axolotl $\left(\sim 23 \mathrm{ng} / \mathrm{mL}^{34}\right)$. This is a clear indication that Axoltol metamorphosis is not dictated solely by $\mathrm{TH}$ levels but that the timing of action is also important, as previously noticed by Brown ${ }^{37}$ and Rose ${ }^{56}$. Therefore, Axolotl metamorphosis is not a compulsory developmental response to a TH stimulus: it is necessary but not sufficient.

\section{$4 \quad$ An early TH dependent transition in Axolotl}

\section{1 ... and a TH sensitive transcriptional response distinct from metamorphosis}

More recently, Kerdivel et al., ${ }^{35}$ characterized the transcriptional changes of an archetypal larval tissue (tailfin) at HTP, asking whether this anatomically unchanging tissue responds to $\mathrm{TH}$. Unexpectedly, tailfin undergoes a strong transcriptional reprogramming (Figure 2a) that displays key features of canonical TH responses (i.e. thbzip and klf9 upregulation) and a clear signature of tissue remodeling. Nonetheless, this gene set shows very little overlap with $\mathrm{TH}$ responsive genes found at later (paedomorph) stage, and with the Xenopus tailfin 
response at the onset of $\mathrm{TH}$ induced metamorphosis (Figure 2A). It is highly significant, however, that the $\mathrm{TH}$ regulated genes in both species are components of the same signaling and metabolic pathways (Figure 2A). A system biology analysis revealed that in both cases, $\mathrm{TH}$ regulated genes channel to the same biological subnetwork, further illustrating similarities of tailfin $\mathrm{TH}$ response in both species (Figure 2A, B). The transcriptional state of this subnetwork, enriched in genes involved in cell fate choice, is believed to act as the molecular switch controlling the tailfin biological response (remodeling vs resorption, Figure 2B). Importantly, the developmental time course of gene expression on untreated animals lead to a similar gene expression dynamic, showing that TH treatment recapitulates well the endogenous gene expression pattern at the HTP. This has a number of biologically relevant implications. First, the transcriptional remodeling of a (apparently unchanged) larval tissue can not be accounted for with the "perpetual larva" model, where animals fail to undergo metamorphosis because of some defect in $\mathrm{TH}$ signaling. This is rather the signature of a developmental transition under the control of $\mathrm{TH}$ signaling, but not immediately followed by metamorphosis. Second, the fact that the same biological pathways are regulated by TH at the HTP in Axolotl and at metamorphosis in Xenopus (despite involving different sets of genes) illustrates the deep evolutionary connection ${ }^{38}$ between TH signaling and developmental transitions. For these reasons, we would like to propose the somewhat provocative hypothesis that the early surge of $\mathrm{TH}$ and the subsequent transcriptional remodeling marks a transition to a non-larval state that correspond to the PETr. In itself, PETr should be considered as a proper TH-dependent developmental transition, that can be uncoupled from metamorphosis.

It is straightforward to add this new transition in Axolotl and Xenopus life cycle: in Axolotl, PETr is mandatory whereas metamorphosis is accessory and depends on additional internal and environmental cues triggering a secondary rise of $\mathrm{TH}$. This statement can be summarized by the "PETr (+M)" pseudo-formula, where parenthesis indicate that the M transition is accessory. In Xenopus, PETr and metamorphosis occur simultaneously or within a very short time frame: "PETr + M". In this context, the perinatal period of mammals can even be thought of as the PETr, without invoking a paradoxically 'subtle' metamorphosis ${ }^{25}$.

\subsection{What are the distinctive features of post embryonic development vs metamorphosis?}

Limb development should clearly be considered as part of post-embryonic development since it proceeds independently from metamorphosis in paedomorphic urodeles ${ }^{36}$. In Axolotl, limb buds are visible as early as stage 45 (once transposed to the equivalent of Xenopus NF nomenclature, see ${ }^{39}$ ), and ossification starts at stage 51-52 when the larva is about two weeks old post-hatching ${ }^{36}$, i.e. the HTP. Not surprisingly, ossification is highly dependent on $\mathrm{TH}$ signaling ${ }^{40}$. In older (one-year old) paedomorphs, the appendicular skeleton (that supports appendages) is already well ossified ${ }^{41}$, with only little histological change after metamorphosis ${ }^{42}$. In the case of Xenopus too, limb growth is a very early anatomical event that precedes other changes attributed to metamorphosis by at least 6 NF stages ${ }^{3}$, which may be a signature that PETr precedes $\mathrm{M}$ even if they are very close to 
each other. This is the "PETr + M" model. The fact that limb development and metamorphosis can be experimentally uncoupled from each other in Xenopus ${ }^{15}$, where limb growth/development is not impaired but mutants fail to undergo metamorphosis, also suggest two distinct transitions.

Neurodevelopment is tightly linked to $\mathrm{TH}$ signaling ${ }^{43-45}$ and is also expected to play a very important role, although it may not be restricted to the PETr transition. In urodeles, hatching is followed by a phase where tadpoles are mostly standing by ('early inactive larvae' stage defined by Joven et al., ${ }^{46}$ ). Later, the carnivorous larvae display more active and complex behaviors (swimming, prey hunting, feeding), sustained by very active phases of neurogenesis ${ }^{46,47}$.

The resorption of aquatic features, such as tailfin and gills are obvious hallmarks of metamorphosis. This also include skin, which undergoes profound remodeling, change of skull shape and the loss of lateral line. The remodeling of many internal organs should also be considered, although they may not be readily accessible to observation, e.g. cell density in epiphyseal cartilage, which is quite high in Axolotl paedomorph but drops sharply at metamorphosis ${ }^{41}$, and immune system remodeling ${ }^{48}$.

\section{$5 \quad$ What to do next?}

Even if our proposal might be provocative in the field of amphibian developmental endocrinology, multiple developmental transitions controlled by the same signaling pathway is not a new fact, as it is commonly found in insects with ecdysone signaling ${ }^{51}$ (also mediated by nuclear receptors).

The $\mathrm{TH}$ responsive period marking the end of larval development is likely a feature shared by all amphibians, and this needs to be experimentally addressed in other taxa with 1) proper measures of $\mathrm{TH}$ variations during development, 2) a detailed characterization of target tissue response and 3) the identification of the transcriptional modules involved. Current work in our lab already suggests that a strong transcriptional reprogramming of taifin occurs between larval and paedomorph stages in L. helveticus, this response being distinct from metamorphosis. The comparative genomics of transcriptional modules might well be the long awaited 'molecular microscope' sensitive enough to test alternative evolutionary hypothesis and discriminate between shared heritage and convergence of the regulatory control of metamorphosis. The situation is complex: paedomorphosis appeared multiple times during the course of evolution ${ }^{25,49}$ and many additional confounding factors (e.g. such as temperature and its impact on growth rate and sensitivity to $\mathrm{TH}^{50}$ ) might be at play. Providing an objective description of Nature and natural processes is ultimately the purpose of Natural History.

After all, paedomorphs may not be 'perpetual' larvae.

\section{Acknowledgments}

We would like to thank D. Buchholz and V. Laudet for fruitful discussions and two anonymous referee for their help improving the manuscript. Our work is funded by the ATM 
funding scheme at MNHN (ATM "XtransVies", "AMADE", "Ambystome" and "Caudanoure"), a MNHN post-doctoral fellowship and the PEPS ExoMod at CNRS ("Triton" to LS). AT did benefit from MNHN pre-doctorate studientship.

\section{References}

1. Elinson RP, del Pino EM. Developmental diversity of amphibians. Wiley Interdiscip Rev Dev Biol. 2012;1(3):345-369. doi:10.1002/wdev.23

2. Paris $M$, Laudet $\mathrm{V}$. The history of a developmental stage: metamorphosis in chordates. Genesis. 2008;46(11):657-672. doi:10.1002/dvg.20443

3. Nieuwkoop PD, Faber J. Normal Table of Xenopus Laevis (Daudin): A Systematic and Chronological Survey of the Development from the Fertilized Egg till the End of Metamorphosis. 1st ed. Amsterdam : North-Holland Pub. Co; 1956.

4. Shi Y-B. Amphibian Metamorphosis: From Morphology to Molecular Biology. John Wiley \& Sons, Inc., New York.; 1999.

5. Holzer G, Laudet V. Thyroid Hormones and Postembryonic Development in Amniotes. In: Current Topics in Developmental Biology. Vol 103. ; 2013:397-425. doi:10.1016/B978-0-12-385979-2.00014-9

6. Thambirajah AA, Koide EM, Imbery JJ, Helbing CC. Contaminant and Environmental Influences on Thyroid Hormone Action in Amphibian Metamorphosis. Front Endocrinol (Lausanne). 2019;10:276. doi:10.3389/fendo.2019.00276

7. Cai L, Brown DD. Expression of type II iodothyronine deiodinase marks the time that a tissue responds to thyroid hormone-induced metamorphosis in Xenopus laevis. Dev Biol. 2004;266(1):87-95. doi:10.1016/J.YDBIO.2003.10.005

8. Denver RJ. Neuroendocrinology of amphibian metamorphosis. Curr Top Dev Biol. 2013;103:195-227. doi:10.1016/B978-0-12-385979-2.00007-1

9. Mendoza A, Navarrete-Ramírez P, Hernández-Puga G, et al. 3,5-T2 is an alternative ligand for the thyroid hormone receptor $\beta 1$. Endocrinology. 2013;154(8):2948-2958. doi:10.1210/en.2013-1030

10. Olvera A, Martyniuk CJ, Buisine N, et al. Differential transcriptome regulation by 3,5T2 and 3',3,5-T3 in brain and liver uncovers novel roles for thyroid hormones in tilapia. Sci Rep. 2017;7(1). doi:10.1038/s41598-017-14913-9

11. Brown DD. The role of deiodinases in amphibian metamorphosis. Thyroid. 2005;15(8):815-821. doi:10.1089/thy.2005.15.815

12. Denver RJ. Environmental stress as a developmental cue: corticotropin-releasing hormone is a proximate mediator of adaptive phenotypic plasticity in amphibian metamorphosis. Horm Behav. 1997;31(2):169-179. doi:10.1006/hbeh.1997.1383 
13. Boorse GC, Denver RJ. Endocrine mechanisms underlying plasticity in metamorphic timing in spadefoot toads. Integr Comp Biol. 2003;43(5):646-657.

doi:10.1093/icb/43.5.646

14. Kühn ER, De Groef B, Grommen SVH, Van der Geyten S, Darras VM. Low submetamorphic doses of dexamethasone and thyroxine induce complete metamorphosis in the axolotl (Ambystoma mexicanum) when injected together. Gen Comp Endocrinol. 2004;137(2):141-147. doi:10.1016/j.ygcen.2004.03.005

15. Sterner ZR, Shewade LH, Mertz KM, Sturgeon SM, Buchholz DR. Glucocorticoid receptor is required for survival through metamorphosis in the frog Xenopus tropicalis. Gen Comp Endocrinol. 2020;291:113419. doi:10.1016/j.ygcen.2020.113419

16. Grimaldi A, Buisine N, Miller T, Shi Y-B, Sachs LM. Mechanisms of thyroid hormone receptor action during development: Lessons from amphibian studies. Biochim Biophys Acta. April 2012. doi:10.1016/j.bbagen.2012.04.020

17. Davidson EH. Emerging properties of animal gene regulatory networks. Nature. 2010;468(7326):911-920. doi:10.1038/nature09645

18. Sachs LM, Buchholz DR. Frogs model man: In vivo thyroid hormone signaling during development. Genesis. 2017;55(1-2). doi:10.1002/dvg.23000

19. Buchholz DR, Shi Y-B. Dual function model revised by thyroid hormone receptor alpha knockout frogs. Gen Comp Endocrinol. 2018;265:214-218. doi:10.1016/j.ygcen.2018.04.020

20. Chatonnet F, Flamant F, Morte B. A temporary compendium of thyroid hormone target genes in brain. Biochim Biophys Acta - Gene Regul Mech. 2015;1849(2):122129. doi:10.1016/j.bbagrm.2014.05.023

21. Chatonnet F, Guyot R, Benoît G, Flamant F. Genome-wide analysis of thyroid hormone receptors shared and specific functions in neural cells. Proc Natl Acad Sci U S A. 2013;110(8):E766--75. doi:10.1073/pnas.1210626110

22. Buchholz DR. More similar than you think: Frog metamorphosis as a model of human perinatal endocrinology. Dev Biol. 2015;408(2):188-195.

doi:10.1016/j.ydbio.2015.02.018

23. Robinson-Rechavi M, Escriva Garcia $\mathrm{H}$, Laudet V. The nuclear receptor superfamily. J Cell Sci. 2003;116(Pt 4):585-586.

24. Holstein TW, Laudet V. Life-history evolution: at the origins of metamorphosis. Curr Biol. 2014;24(4):R159-61. doi:10.1016/j.cub.2014.01.003

25. Laudet V. The origins and evolution of vertebrate metamorphosis. Curr Biol. 2011;21(18):R726--37. doi:10.1016/j.cub.2011.07.030 
26. Bonett RM. An Integrative Endocrine Model for the Evolution of Developmental Timing and Life History of Plethodontids and Other Salamanders. Copeia. 2016;104(1):209-221. doi:10.1643/OT-15-269

27. Denoël M, Ficetola GF. Heterochrony in a complex world: disentangling environmental processes of facultative paedomorphosis in an amphibian. Colli $\mathrm{G}$, ed. J Anim Ecol. 2014;83(3):606-615. doi:10.1111/1365-2656.12173

28. Beachy CK, Ryan TJ, Bonett RM. How Metamorphosis Is Different in Plethodontids: Larval Life History Perspectives on Life-Cycle Evolution. Herpetologica. 2017;73(3):252-258. doi:10.1655/Herpetologica-D-16-00083.1

29. LYNN WG. TYPES OF AMPHIBIAN METAMORPHOSIS. Am Zool. 1961;1(1):151161. doi:10.1093/icb/1.1.151

30. De Groef B, Grommen SVH, Darras VM. Forever young: Endocrinology of paedomorphosis in the Mexican axolotl (Ambystoma mexicanum). Gen Comp Endocrinol. 2018;266:194-201. doi:10.1016/j.ygcen.2018.05.016

31. Safi R, Bertrand S, Marchand O, et al. The axolotl (Ambystoma mexicanum), a neotenic amphibian, expresses functional thyroid hormone receptors. Endocrinology. 2004;145(2):760-772. doi:10.1210/en.2003-0913

32. Darras VM, Kühn ER. Effects of TRH, bovine TSH, and pituitary extracts on thyroidal T4 release in Ambystoma mexicanum. Gen Comp Endocrinol. 1983;51(2):286-291.

33. Aran RP, Steffen MA, Martin SD, Lopez OI, Bonett RM. Reduced effects of thyroid hormone on gene expression and metamorphosis in a paedomorphic plethodontid salamander. J Exp Zool Part B Mol Dev Evol. 2014;322(5):294-303. doi:10.1002/jez.b.22580

34. Rosenkilde P, Mogensen E, Centervall G, Jørgensen OS. Peaks of neuronal membrane antigen and thyroxine in larval development of the Mexican axolotl. Gen Comp Endocrinol. 1982;48(4):504-514.

35. Kerdivel G, Blugeon C, Fund C, Rigolet M, Sachs LM, Buisine N. Opposite T3 Response of ACTG1-FOS Subnetwork Differentiate Tailfin Fate in Xenopus Tadpole and Post-hatching Axolotl. Front Endocrinol (Lausanne). 2019;10:194. doi:10.3389/fendo.2019.00194

36. Schreckenberg GM, Jacobson AG. Normal stages of development of the axolotl. Ambystoma mexicanum. Dev Biol. 1975;42(2):391-400.

37. Brown DD. The role of thyroid hormone in zebrafish and axolotl development. Proc Natl Acad Sci U S A. 1997;94(24):13011-13016.

38. Shubin N, Tabin C, Carroll S. Deep homology and the origins of evolutionary novelty. Nature. 2009;457(7231):818-823. doi:10.1038/nature07891 
39. Nye HLD, Cameron JA, Chernoff EAG, Stocum DL. Extending the table of stages of normal development of the axolotl: limb development. Dev Dyn. 2003;226(3):555560. doi:10.1002/dvdy.10237

40. Williams GR. Thyroid Hormone Actions in Cartilage and Bone. Eur Thyroid J. 2012;2(1):3-13. doi:10.1159/000345548

41. Thampi P, Liu J, Zeng Z, MacLeod JN. Changes in the appendicular skeleton during metamorphosis in the axolotl salamander (Ambystoma mexicanum). J Anat. 2018;233(4):468-477. doi:10.1111/joa.12846

42. Demircan T, IIlhan AE, Aytürk N, Yıldırım B, Öztürk G, Keskin İ. A histological atlas of the tissues and organs of neotenic and metamorphosed axolotl. Acta Histochem. 2016. doi:10.1016/j.acthis.2016.07.006

43. De Escobar GM, Obregón MJ, Del Rey FE. Role of thyroid hormone during early brain development. In: European Journal of Endocrinology, Supplement. Vol 151. Eur J Endocrinol; 2004. doi:10.1530/eje.0.151u025

44. Williams GR. Neurodevelopmental and neurophysiological actions of thyroid hormone. J Neuroendocrinol. 2008;20(6):784-794. doi:10.1111/j.13652826.2008.01733.x

45. Forrest $D$, Reh TA, Rüsch $A$. Neurodevelopmental control by thyroid hormone receptors. Curr Opin Neurobiol. 2002;12(1):49-56. doi:10.1016/s09594388(02)00289-1

46. Joven A, Simon A. Homeostatic and regenerative neurogenesis in salamanders. Prog Neurobiol. 2018;170:81-98. doi:10.1016/j.pneurobio.2018.04.006

47. Joven A, Wang H, Pinheiro T, Hameed LS, Belnoue L, Simon A. Cellular basis of brain maturation and acquisition of complex behaviors in salamanders. Dev. 2018;145(1). doi:10.1242/dev.160051

48. Ussing AP, Rosenkilde P. Effect of Induced Metamorphosis on the Immune System of the Axolotl, Ambystoma mexicanum. Gen Comp Endocrinol. 1995;97(3):308-319. doi:10.1006/GCEN.1995.1031

49. Bonett RM, Steffen MA, Lambert SM, Wiens JJ, Chippindale PT. EVOLUTION OF PAEDOMORPHOSIS IN PLETHODONTID SALAMANDERS: ECOLOGICAL CORRELATES AND RE-EVOLUTION OF METAMORPHOSIS. Evolution ( $N$ Y). 2014;68(2):466-482. doi:10.1111/evo.12274

50. Hickerson CAM, Barker EL, Beachy CK. Determinants of metamorphic timing in the black-bellied salamander, Desmognathus quadramaculatus. Southeast Nat. 2005;4(1):3350. doi:10.1656/1528-7092(2005)004[0033:DOMTIT]2.0.CO;2

\section{Figures Legend}


Figure 1: Life cycle of amphibian species. Most Anurans (A) and Urodeles (B) display a biphasic life cycle, where the transition marking the end of larval development (Post Embryonic Transition, PETr) starts with a transient rise of thyroid hormones (TH) followed by the resorption of larval characters (e.g. tailfin, green). This transition corresponds to metamorphosis (M). In the case of direct development (C), which is found in anurans and urodeles, juveniles hatch directly from the egg and metamorphosis occurs in ovo. Some urodeles display a more complex life cycle (D) where animals reach sexual maturity before metamorphosis (paedomorph), which can be accessory but is still dependent on a transient surge of $\mathrm{TH}$ (dashed line). At the early peak of $\mathrm{TH}$, paedomorph tailfin undergoes a TH-dependent transcriptional remodeling, indicative of a transition to a non-larval state (blue). We argue that this early transition is the PETr. Consequently, metamorphosis and PETr are two distinct life cycle transitions that can be uncoupled from each other and can occur at different developmental times. This naturally leads to complex life cycles ("PETr $(+M) ")$. Bi-phasic life cycles then represent a special case where they occur very close to each other ("PETr + M"). Digital paintings not to scale.

Figure 2: Control of tailfin fate in Axolotl and Xenopus. The experimental workflow (A) combines functional genomics, pathway analysis and network biology to efficiently reduce the large lists of regulated genes down to a single subnetwork of functional interactions. The key findings from ${ }^{35}$ are indicated. In the new model (B), the control of tailfin fate (resorption vs remodeling) is dictated by the differential regulation of the ACTG1-FOS subnetwork. Network nodes correspond to gene products. Color (red and blue) reflect their transcriptional response (induced or repressed, respectively). Tailfin, an archetype of larval tissue, is highlighted in green. DE genes: differentially expressed genes. Digital paintings not to scale. 